\title{
Indigenous Sign Language of Far North Queensland
}

\author{
Suzannah J. Jackson \\ James Cook University \\ suzannah.oreilly@my.jcu.edu.au
}

\section{Introduction}

Deaf Indigenous people living in urban centres of Far North Queensland (FNQ) claim to use a signed language system named Indigenous Sign Language or ISL. To date, there has been little investigation into both the origins and linguistic features of ISL. Consequently the language has been classified in the literature into the categories of either contact language (Johnston \& Schembri, 2007) or idiolect (Fayd'herbe \& Teuma, 2010). Nevertheless, Deaf Indigenous people in FNQ, who are the principal users of ISL regard their language as a functioning system of communication, derived from the Australian Aboriginal Sign Languages (AASLs) and Torres Strait Signed Languages used throughout the region. In this paper, new evidence is presented in two parts: Qualitative data elicited from a small group of Deaf Indigenous people outlining the social context supporting the acquisition of AASLs; and evidence from the ISL lexicon showing a direct connection between AASL, Torres Strait Signed Languages and ISL. The paper discusses the idea that ISL may be comprised of several contact languages, reflecting a mixed language environment that has mediated the preservation of AASLs in an environment of language decline.

\section{The Deaf Indigenous Community of Far North Queensland}

The Deaf Indigenous community of FNQ comprises people who reside in urban and remote community areas within the FNQ geographical boundary. This boundary extends approximately from Yarrabah in the south, west to West Cape York and north to encompass the Torres Strait Islands (O'Reilly, 2005). Figure 1 is a map of FNQ showing the locations of spoken Indigenous languages mentioned in this study. Please note that not all spoken language groups are included in the map. 
Figure 1: Locations of spoken Indigenous Languages in FNQ

\section{Australian Aboriginal Languages of Far North Queensland}

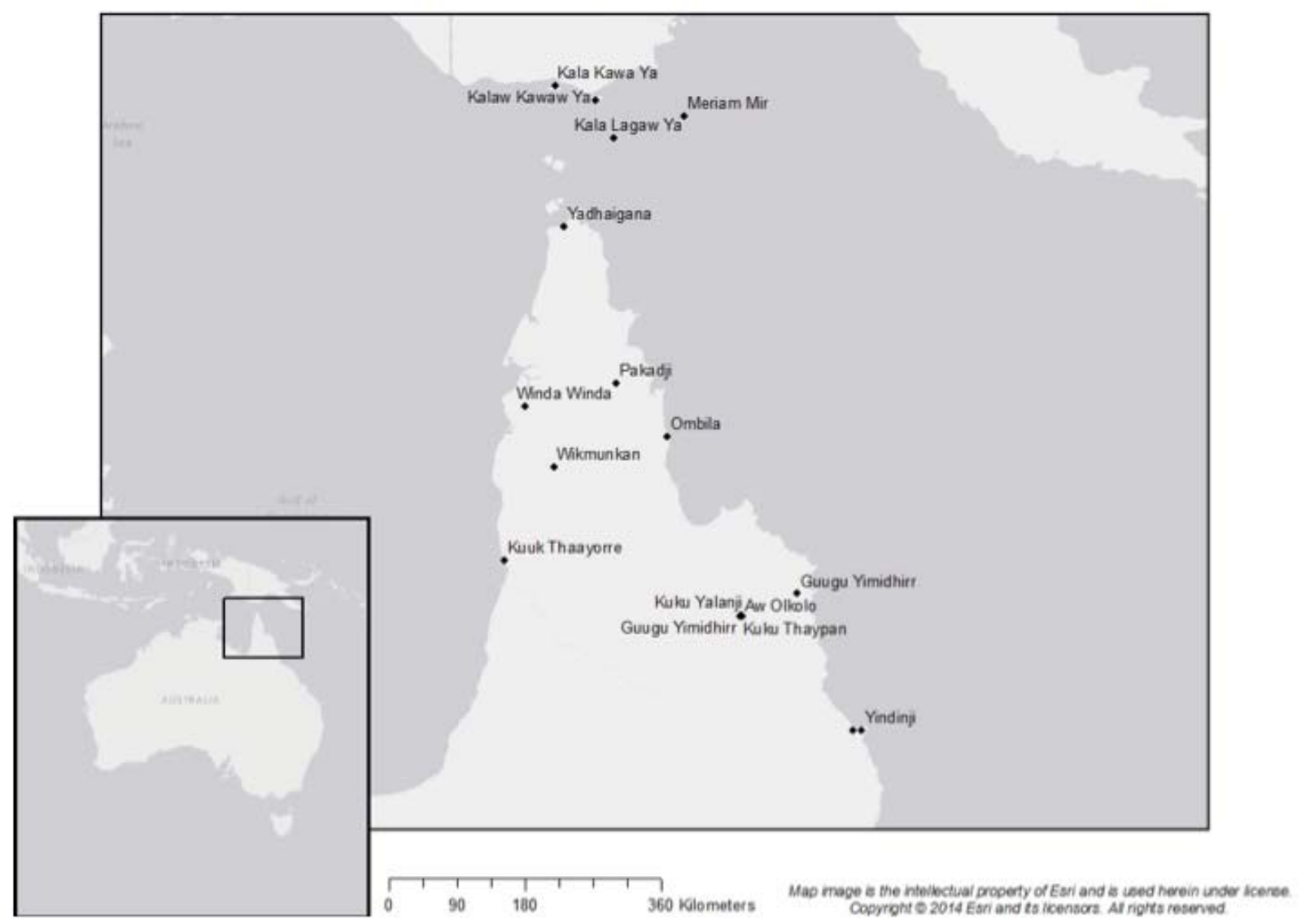

There are approximately 35 Aboriginal languages spoken in the Cape York region among the various societies. However to the north of the Australian mainland lie a less known series of islands that comprise the Torres Straits. The traditional custodians of the Torres Strait Islands are of Melanesian descent whose traditional way of life prior to settlement was based on fishing, hunting, trade relationships, kinship, reciprocity and spirituality (Mina Mir Lo Ailan Mun, 2000). Present day Torres Strait life is modernised with tourism and trade of food, weapons and artefacts between Cape York communities and Papua New Guinea comprising a significant part of the Torres Strait economy. Linguistically, there are three main spoken languages in the Torres Strait and these include Meriam Mir spoken in the East, Kala Lagaw Ya spoken in the Central and West islands and Kala Kawa Ya is spoken among the northern islands. Over time, Torres Strait Island Creole has evolved as a lingua franca and extends across inhabited islands.

Cairns represents a main urban centre where many Deaf Indigenous people from Cape York and the Torres Strait Islands choose to live. Historically, it functioned as a centralised hub where many Deaf Indigenous community members resided as children to attend specialised schooling programs. Some of these deaf children were removed at a very young age, placed into "all-white classrooms" and were reported to have suffered traumatic effects as a result (Fayd'herbe \& Teuma, 2010). The contemporary community however, is strongly connected with members enjoying many social and vocational activities. FNQ Deaf Indigenous people are politically active, have strong social justice values and many are involved in organising social events, for instance, the Deaf cultural dancing troupe called the Deaf Indigenous Dance Group 
or DIDG. A proportion of Deaf Indigenous people have gained employment with Education Queensland in positions called Auslan Learning Models (ALM's) for the purpose of modelling ISL to younger Deaf Indigenous children and to act as a cultural bridge between the school and the home community. People in these positions are employed for their linguistic and cross-cultural competencies in that they can effectively function across multicultural and multilingual settings.

\section{The Origins of Indigenous Sign Language}

An important research question is whether the FNQ ISL used among Deaf Indigenous people is a derivative of the AASLs and Torres Strait Signed Languages used throughout the region. AASLs once proliferated across the Australia, however like their spoken counterparts, have faced decline since colonisation. It is estimated that there has been a decrease in the percentage of people speaking Indigenous languages from $100 \%$ in 1800 to $13 \%$ in 1996 (McConvell \& Thieberger, 2001). Early documentation shows many of these languages had parallel sign language systems exemplified by the highly developed Warlpiri sign language of the North Central Desert area of Australia (Wright, 1980; Power, 2013). Like aboriginal spoken languages, AASLs are subject to dialectic variation, for example, those found in the Cape York region of North Queensland including the Wikmunkan on Western Cape and Winda Winda in the North Western Cape, are differentiated from dialects in the North Central Desert area (Kendon, 1988).

Historical observations of AASLs in East Cape York date back to 1908 (Roth, 1908). Roth reported a number of signs used by the Guugu Yimidhirr people of the Hopevale area. Sixty years later, West (1961-1965) corroborated this evidence with film footage of Guugu Yimidhirr women and men performing the same signs. Kendon observed that it was not likely that the Guugu Yimidhirr dialect was well developed stating that it was 'highly pantomimic and improvisational in character' (1988). By contrast, Kendon claimed that sign languages in the Northern Cape contained markers of a more developed language including one handed signing that used rapid hand differentiation. In these areas, the principle users of the sign language were characteristically hearing females whom Kendon deemed to be highly proficient.

The function of sign language lexicons in traditional aboriginal societies was contextualised to the cultural circumstance. In some instances, sign language was used as an alternate option to supplement spoken language use where speaking and signing occurred at the same time. This type of code mixing is known as code blending and has been studied in bimodal bilingual populations (Emmorey, Borinstein, Thompson \& Gollan, 2008). Code blending is the ability to articulate signs and words simultaneously and Kendon observed this phenomenon where spoken instructions given by a bilingual mother to her children were accompanied by signing, most likely for emphasis (1988). In contrast to code blending, sign language was used in other social contexts to entirely replace spoken languages rather than function as an accompaniment. For instance, West (1961-1965) observed women in Northern Cape tribes such as the Ombila and the Pakadji, were required to observe cultural taboos for extended periods of up to one to two years' duration. In these cases, the requirement to follow strict cultural protocols meant sign language represented the dominant form of communication.

Situational demands may have supported flexibility in the use of sign language in traditional aboriginal societies allowing for switches between code blending and complete sign language use. Despite this flexibility, the AASLs observed in FNQ are regarded as alternate sign language systems as opposed to primary systems. Primary signed languages are those used by people (for the most part Deaf people) as their chief or in some cases, only linguistic form of communication (Kendon, 1988). By contrast, alternate signed languages are those used by people who are competent in at least one spoken language. Despite the fact that at times 
AASL was the only form of communication for female hearing users, they were, for the most part, competent articulators of a spoken language.

\section{The Use of Australian Aboriginal Sign Language by Urban Deaf Indigenous People}

The extensive use of AASLs in traditional aboriginal societies throughout FNQ raises the question of whether deaf members employ these lexicons in a primary capacity. Given sign language would have been the principal mode for deaf individuals, it is arguable that they would have been exposed to the AASLs in use in their communities. There are no records of deaf aboriginal users of AASL in FNQ prior to European settlement however in this paper, new evidence is presented in two parts: Qualitative date outlining the social context supporting the acquisition of AASLs of a small group of Deaf Indigenous people; and evidence from the ISL lexicon that shows a direct connection between AASL and ISL.

\section{The Social Context to Learning an AASL}

In this section, qualitative data is presented from interviews conducted by the author with Deaf Indigenous community members. The interviews were held at a small gathering and informed consent was gained from all participants involved. PR is a profoundly deaf Aboriginal Elder from Laura in Cape York. The most prominent language spoken in Laura is Aw Olkolo, however other languages that are also spoken include Kuku Thaypan, Kuku Yalanji and Guugu Yimithirr. PR describes growing up with an AASL:

"It's a really visual language, and you just grow up out in that community and you know that it's normal because everyone does it, not just your parents. And when you become older, you realise that it's a cultural language, and it's a very old language going way back to even before white people came". PR then describes an experience with a hearing elder: "I remember I was with a group up in an aboriginal community in Cape York, and it was the first time that I was involved with that community of hearing people. There were also lots of aboriginal elders up there too. And one very, very old man said, "you come here" and I said, "me, you don't need me" and he said, "yep, come on, come on" and I knew that I had to respect him, and go up to him, and I didn't know how on earth I was going to communicate with him as I was the only deaf person there. He was talking about fighting for the land and I really didn't understand what he was talking about, but I knew I had to try and learn. Then he did a bit of sign and I was like 'wow' and said, "yes, yes" and suddenly we were communicating. He just didn't care that I was deaf; he said "come on, come on, I want you to learn about the culture and the land, and what we're here for in this meeting", and I was just so in awe, and he could sign, and it was just wonderful".

Like AASLs, the signed languages used among the Torres Strait Island communities may also have been assimilated into ISL. Early reports made by Sidney Ray in 1907 during a Cambridge Anthropological expedition to the Torres Straits revealed extensive sign language use. Modern reports by Deaf Indigenous members who grew up in the Torres Strait Islands claim the sign language they use is derived from their hearing parents. For instance, SF is a profoundly Deaf member of the Badu Island community in the Torres Straits where the main language spoken is Kala Lagaw Ya. SF describes the origins of her sign language as such:

"ISL was there in the olden days, and they did pass it through the generations, the same as the spoken language. I mean, I know that my language is my own language 
that I've inherited from my parents, and I understand that other indigenous people have their own language as well, that they've learnt from their parents too. And when we talk to each other, we like to learn each other's language, definitely. But we do know that they're all different".

The following experience demonstrates the use of ISL in the broader Deaf Indigenous community. AW is a profoundly Deaf elder from Saibai Island in the Torres Straits where the local language spoken is called Kalaw Kawaw Ya. AW spends her time residing between Thursday Island and Cairns. At a young age, AW was relocated to Cairns to attend school where the method of instruction was Signed English, an out-dated form of communication. In her adult years, AW developed proficiency in Auslan and she describes her experiences using Signed English, ISL and Auslan:

"ISL, I feel, is really comfortable for all of us (in the Deaf Indigenous community), and we were really like 'oh, we can't be bothered with white sign language'. And we would say 'why are you forcing us to do Signed English, or white sign language' and we were really confused and felt really uncomfortable about it. But we were always very patient and we knew that we'd have to go out and meet different people in the normal deaf community. And we'd have to change. It took about five years to change to Auslan signing. But lucky because I was very flexible, maybe because I already had ISL, I was able to learn it. And then we changed as well; we go from Auslan to ISL and then if we meet someone who is really strict with Signed English we have to change back to that to, but that's really hard. When we're signing here, we feel really comfortable".

The experiences described by all three participants suggests ISL may incorporate the AASL and Torres Strait signs that Deaf Indigenous people have acquired from hearing signers in their respective home communities.

\section{Linking ISL to AASLs and Torres Strait Signed Languages}

The following figures depict signs in the ISL lexicon used by two members of the Cairns Deaf Indigenous community that are linked to signs from their respective home communities. Figure 2 shows signs used by AW who resides in Cairns but originates from Saibai Island in the Torres Strait. AW is unique in that as a child, she acquired AASL from her mother who was raised in the Aboriginal community of Cherbourg in Queensland and Torres Strait Signed Language from her father who is from Saibai Island. In Figure 2, AW is signing the AASL and Torres Strait Signed Language variations for the sign woman.

Figure 2: AW signs the variation for the sign "woman" on the left in AASL and on the right in Torres Strait Signed Language.
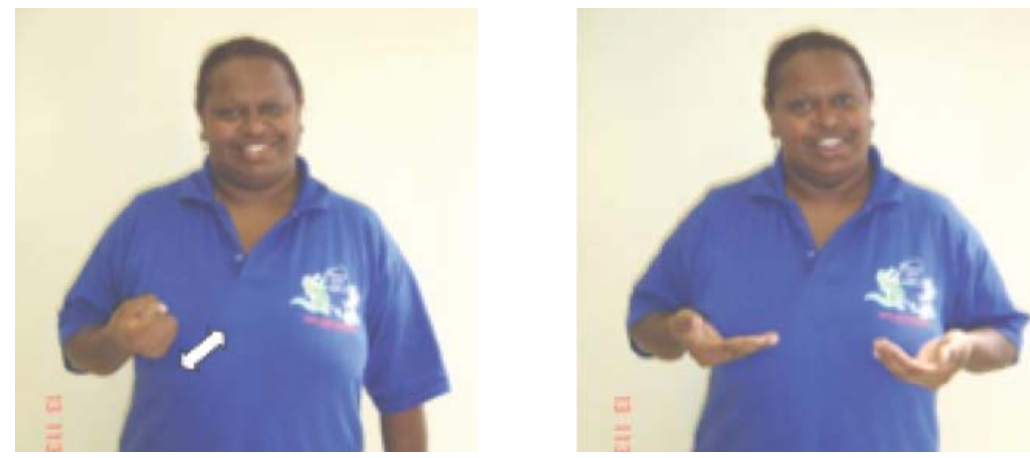
Figure 3 compares signs used by a 19- year old Deaf Indigenous man (PC) with those used by an hearing Elder (MA), from the same remote Northern Cape community. PC resides in Cairns however originates from the community of Pormpuraaw in the north west of Cape York, a community where MA has lived for the duration of her life and is a user of the local language called Kuuk Thaayorre. Figure 3 shows PC and MA using the same signs for toilet, sister and nephew/niece. The AASL used by PC is likely to have been acquired during sign language contact interactions that occurred in childhood, prior to his relocation to Cairns. The similarity between modern usage of signs constructed in ISL and signs used in AASL is reflected in these figures.

Figure 3: A comparison of signs used by young Deaf Indigenous Man and a Hearing Elder from the same remote $F N Q$ community

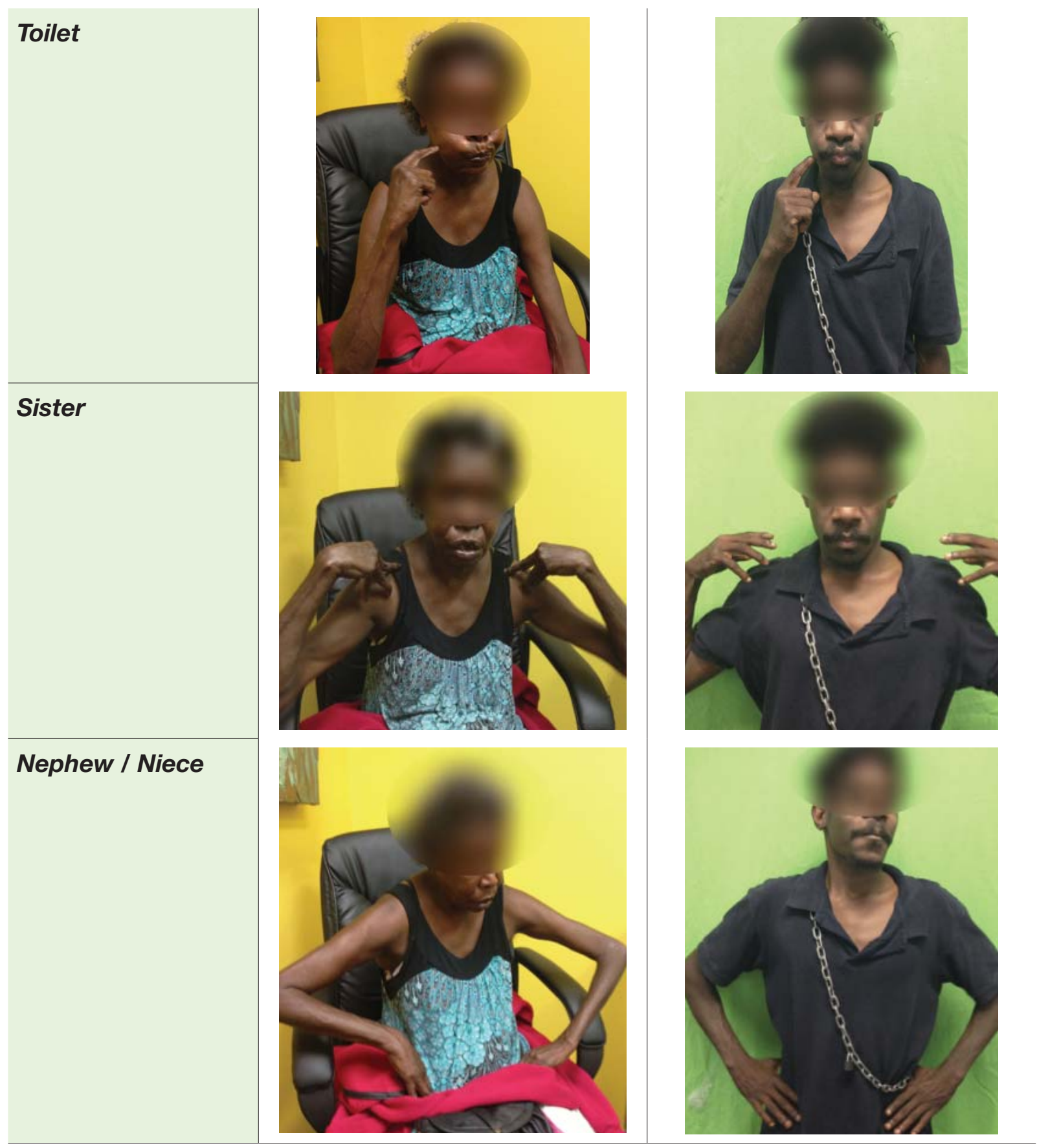


In summary, the urban ISL users in this study have originated from several remote communities throughout FNQ. When they converse in ISL, they bring with them a combination of contact signed languages. The users describe a multilingual environment where interlocutors may code switch between Auslan and ISL. However, to what extent contact signed languages are exchanged and whether this occurs in a primary or alternate capacity, requires further analysis.

\section{Discussion}

In this paper, evidence has been provided demonstrating important links between signs used in both the AASL and ISL lexicons. Anecdotal evidence taken from Deaf Indigenous users of ISL show some acquisition of AASLs and Torres Strait Signed Languages from hearing members of the remote community from which they originate. In addition, when urban Deaf Indigenous people converge, the linguistic environment reflects a multilingual interaction of several contact languages with possible code switches between ISL and Auslan. The process of how AASL-ISL language transmission occurs, for example, whether through the converging of contact languages or via another mechanism, is an important research question. In addition, the question of whether Deaf Indigenous signers use ISL in a primary capacity as the result of language mixing also remains unanswered.

One possible answer involves the influence of the early schooling environment of Deaf Indigenous children. Recall that many of these children were exposed to AASLs before being relocated to urban centres for schooling. It is possible that the mixing of contact languages in this novel context gave rise to a developing ISL structure. Kendon observed such language extension in deaf people in remote communities, whom he claimed had developed their own language structure (1988). Moreover, a similar phenomenon occurred in the development of Light Warlpiri, where code switching between two contact languages transitioned into a mixed language situation (O'Shannessey, 2012). A mixed language emerges in a context of community bilingualism where structural and lexical elements from two source languages are combined to the extent that neither language is dominant. At this stage though, there is very little evidence to show that ISL involves a mixed language situation representing a limitation of the present study. Moreover, it is not clear whether the mixing of contact languages in the case of ISL comprises a mixed language or a simply lingua franca with borrowings of signs from differing AASLs and Torres Strait Signed Languages. Besides, there are other pressing issues including whether ISL is a language in its own right or a dialect of Auslan. What is certain is more research is required in order to elucidate the linguistic status of ISL. In particular, research into ISL at this time appears crucial given the possibility it has mediated the preservation of AASLs and Torres Strait Signed Languages of the FNQ region in an environment of language decline.

\section{References}

Emmorey, K., Borinstein, H.B., Thompson, R., \& Gollan, T.H. (2008). Bimodal bilingualism. Bilingualism: Language and Cognition, 11, 43-61.

Fayd'herbe, K. \& Teuma, R. (2010). Interpreting for Indigenous Auslan Deaf clients in Far North Queensland within the legal context. In R. Locker McKee \& J.E. Davis (Eds.), Interpreting in Multilingual, multicultural Contexts. (Vol. 7). Washington, DC: Gallaudet University Press.

Johnston, T. \& Schembri, A. (2007). Australian Sign Language (Auslan): An introduction to sign language linguistics. Cambridge: Cambridge University Press.

Kendon, A. (1988). Signed Languages of Aboriginal Australia: Cultural, Semiotic and Communication Perspectives. Cambridge: Cambridge University Press. 
Mina Mir Lo Ailan Mun. (2000). Proper communication with Torres Strait Islander peoples. Brisbane, QLD: Department of Aboriginal and Torres Strait Islander Partnerships.

McConvell, P. \& Thieberger, N. (2001). State of Indigenous languages in Australia - 2001. Australia State of the Environmental Second Technical Paper Series (Natural and Cultural heritage). Canberra: Department of the Environment and Heritage. Retrieved from http://www.ea.gov.au/soe/ techpapers/index.html

O'Reilly, S. (2005). Indigenous Australian Sign Language and Culture: The interpreting and access needs of Deaf people who are Aboriginal and/or Torres Strait Islander in Far North Queensland. Cairns, QLD: Association of Sign Language Interpreters Australia Winterschool.

O'Shannessy, C. (2012). The role of codeswitched input to children in the origin of a new mixed language. Linguistics, 50(2), 305-340.

Power, D. (2013). Australian Aboriginal Deaf people and Aboriginal Sign Language. Sign Language Studies, 13(2), 264-277.

Ray, S.H. (1907). Reports of the Cambridge Anthropological Expedition to Torres Straits: Volume III Linguistics. Cambridge: Cambridge University Press.

Roth, W.E. (1908). Miscellaneous Papers. Sydney, NSW: Australian Trustees of the Australian Museum.

West, L.M. (1961-1965). Sign Language Films. Canberra, ACT: Australian Institute of Aboriginal Studies.

Wright, C.D. (1980). Walpiri hand talk: an illustrated dictionary of hand signs used by the Walpiri people of central Australia. Darwin, NT: Northern Territory Department of Education. 